\title{
HIDROGÉIS DE PEG-CO-ACRILAMIDA COMO SISTEMAS DE LIBERAÇÃO MODIFICADA DE BIOATIVOS.
}

\author{
Natali P. Souza*, Fernanda M. Croisfelt, Priscila G. Mazzola, Elias B. Tambourgi.
}

\section{Resumo}

Por apresentarem satisfatórias propriedades de biodegradação, biocompatibilidade e termossensibilidade, os hidrogéis à base de Polietilenoglicol (PEG) exercem papel importante em sistemas inteligentes de liberação de substâncias. Dentre as diversas propriedades da bromelina, protease encontrada em Abacaxis (Ananas comosus L.), destacam-se suas atividades fibrinolíticas e anti-inflamatórias. Tendo em vista esses dois fatores, a possível associação de hidrogéis e bromelina em um dispositivo de liberação modificada tende a ser uma promissora alternativa não-invasiva para o tratamento de queimadura e estados inflamatórios tópicos.

\section{Palavras-chave:}

Hidrogel, bromelina, liberação controlada.

\section{Introdução}

Hidrogéis são sistemas poliméricos de redes tridimensionais que podem ser amplamente intumescidos com água ${ }^{1}$. Atualmente, os hidrogéis têm conquistado cada vez mais atenção por sua promissora variedade de aplicações no âmbito farmacêutico, sendo uma destas, a liberação controlada de substâncias ${ }^{2}$. Os hidrogéis à base de polietilenoglicol possuem boas propriedades de biodegradação e biocompatibilidade ${ }^{3}$. Além disso, o PEG pode ser facilmente controlado e é um material termossensível, o que o faz importante do ponto de vista farmacêutico, podendo exercer papel notável em hidrogéis inteligentes de liberação modificada de bioativos ${ }^{4}$.

A bromelina, que está presente principalmente no extrato bruto do abacaxi (Ananas comosus L.), possui, dentre outras, propriedades fibrinolítica, antitrombótica e antiinflamatória, as quais já foram documentadas em estudos in vitro e in vivo ${ }^{5}$, e representam funções úteis para as indústrias farmacêuticas ${ }^{6}$.

O objetivo deste trabalho foi sintetizar e descrever 0 hidrogel de PEG contendo bromelina com finalidade tópica de liberação modificada deste ativo.

\section{Resultados e Discussão}

Os hidrogéis foram polimerizados com sucesso constatando-se a ocorrência rápida de copolimerização entre a bis-acrilamida e o polietilenoglicol. A quantificação de proteínas totais e a determinação da atividade enzimática do material na incorporação da bromelina pelo hidrogel e na liberação deste ativo pelo mesmo, também foram analisadas com sucesso; esse estudo foi realizado às temperaturas de 25 e $37^{\circ} \mathrm{C}$.

Quanto à quantificação da proteína total $(\mu \mathrm{g} / \mathrm{ml})$ na incorporação da bromelina pelo material, à temperatura de $25^{\circ} \mathrm{C}$, nos primeiros tempos de análise houve um aumento progressivo da incorporação de bromelina pelo hidrogel, incorporação a qual começa a decair no tempo de 24 horas. Já à $37^{\circ} \mathrm{C}$, a incorporação da bromelina sofreu um decaimento linear desde o primeiro tempo estudado, mostrando que talvez a temperatura em questão não seja a ideal para a ocorrência de absorção do hidrogel.
A determinação da atividade enzimática $(\mathrm{U} / \mathrm{mL})$ na incorporação da bromelina, tanto para $25^{\circ} \mathrm{C}$ quanto para $37^{\circ} \mathrm{C}$, não se manteve constante, mas teve aumentos e quedas intercalados. Este fato pode ser devido à instabilidade da bromelina.

Em relação à liberação da bromelina pelo hidrogel, a quantificação da proteína total à $25^{\circ} \mathrm{C}$, ou seja, a quantidade de proteína liberada pelo material, decaiu progressivamente até certo tempo, quando aumentou discretamente até tornar-se constante. À $37^{\circ} \mathrm{C}$, notou-se que tal liberação iniciou-se alta e decaiu com o tempo, tornando-se constante posteriormente.

$A$ atividade enzimática após a liberação da bromelina pelo hidrogel, tanto para $25^{\circ} \mathrm{C}$ quanto para $37^{\circ} \mathrm{C}$, não se manteve, com pico em determinado tempo e queda que se manteve até o final da análise.

\section{Conclusões}

Os resultados dos experimentos realizados demonstraram que ocorre co-polimerização satisfatória entre o polietilenoglicol e a bis-acrilamida, resultando na formação adequada de um hidrogel. Além disso, este hidrogel sintetizado demonstrou-se capaz de absorver a solução de bromelina e de liberá-la, indicando que há a possibilidade do mesmo poder ser utilizado como um sistema de liberação modificada da proteína.

\footnotetext{
${ }^{1}$ AHMED, E. M. et al. An innovative method for preparation of nanometal hydroxide superabsorbent hydrogel. Carbohydrate Polymers, v. 91, n. 2, p. 693-8, Jan 16 2013. ISSN 0144-8617

${ }^{2}$ LIN, C. C.; METTERS, A. T. Hydrogels in controlled release formulations: network design and mathematical modeling. Adv Drug Deliv Rev, v. 58, n. 12-13, p. 1379-408, Nov 30 2006. ISSN 0169-409X

${ }^{3}$ ALEXANDER, A. et al. Polyethylene glycol (PEG)-Poly(Nisopropylacrylamide) (PNIPAAm) based thermosensitive injectable hydrogels for biomedical applications. Eur J Pharm Biopharm, v. 88, n. 3, p. 575-85, Nov 2014. ISSN 0939-6411

${ }^{4}$ ALEXANDER, A. et al. Poly(ethylene glycol)-poly(lactic-co-glycolic acid) based thermosensitive injectable hydrogels for biomedical applications. Journal Control Release, v. 172, n. 3, p. 715-29, Dec 28 2013. ISSN 01683659 .

${ }^{5}$ PAVAN, R. et al. Properties and therapeutic application of bromelain: a review. Biotechnol Res Int, v. 2012, p. 976203, 2012

${ }^{6}$ KETNAWA, S.; CHAIWUT, P.; RAWDKUEN, S. Extraction of bromelain from pineapple peels. Food Sci Technol Int, v. 17, n. 4, p. 395-402, Aug 2011. ISSN 1082-0132
} 